Original Research Article

\title{
Effect of various cardiovascular risk factors on oxidative stress markers in post menopausal women
}

\author{
Subrat Kumar Tripathy*, Pramila Kumari Mishra
}

\begin{abstract}
${ }^{1}$ Department of Biochemistry, Institute of Medical Sciences and Sum Hospital, Siksha O Anusandhan University, Bhubaneswar, India ${ }^{2}$ Department of Biochemistry, Maharaja Krishna Chandra Gajapati Medical College (MKCG), Berehampur, India
\end{abstract}

Received: 07 May 2017 Accepted: 31 May 2017

\section{*Correspondence to: Dr. Subrat Kumar Tripathy, Email: subrat49@ rediffmail.com}

Copyright: (C) the author(s), publisher and licensee Medip Academy. This is an openaccess article distributed under the terms of the Creative Commons Attribution NonCommercial License, which permits unrestricted noncommercial use, distribution, and reproduction in any medium, provided the original work is properly cited.

\begin{abstract}
Background: The objectives was to study the association between oxidative stress and various cardiovascular risk factors individually and also there cumulative effect in post-menopausal women.

Methods: 50 postmenopausal women with cardiovascular risk factors like hyperglycemia, hypertension, high Body Mass Index and Hyperlipidaemia were selected and burden of various cardiovascular risk factors in them is noted and also compared with 50 age matched apparently healthy post menopausal controls. Malon-di-aldehyde (MDA), vitaminE and vitamin $\mathrm{C}$ were taken to assess oxidative stress status. ANOVA was applied to find the effect of individual risk factor on oxidative stress and Student's t-test was applied to compare between cases with single risk factors and multiple risk factors.

Results: It was found that though all cardiovascular risk factors increase oxidative stress significantly but none of them has significant association in comparison to others ( $\mathrm{F}$ value $0.37,0.88$ and 0.62 for MDA, vitamin $\mathrm{E}$ and $\mathrm{C}$ respectively). However, MDA value found in cases with multiple risk factors when compared with that of cases with single risk factor was found to be statistically significant $(\mathrm{P}<0.001)$. Similarly, the decrease in vitamin $\mathrm{E}$ in cases with multiple risk factors when compared with single risk factor cases was found to be significant. ( $\mathrm{P}<0.01)$ and vitamin $\mathrm{C}$ in women with multiple risk factors was decreased in comparison to women with a single risk factor and was significant $(\mathrm{P}<0.001)$.

Conclusions: The study shows that all the risk factors are equally responsible for increase in oxidative stress and multiple risk factors increase the oxidative stress significantly in comparison to any single risk factor.
\end{abstract}

Keywords: Menopause, MDA, Oxidative stress, Vitamin C, Vitamin E

\section{INTRODUCTION}

Menopause is a normal occurrence in the life of every woman. It is not just cessation of menstruation; it is depletion of ovarian follicles, leading to decrease in ovarian hormones. By WHO the term menopause is defined as dating from the final menstrual period, regardless whether the menopause is induced or spontaneous. ${ }^{1}$ In 1000 BC life expectancy was only 18 year, by $100 \mathrm{BC}$ the time of Julius Caesar it had reached 25 year.
In 1900 in US the life expectancy had reached 49 year and now it is 79.7 year for women. ${ }^{2}$ In India the mean age of menopause is 49.4 year and 130 million Indian women live beyond menopause into old age in 2015. By the age $48-492 / 3^{\text {rd }}$ of women are menopausal. So the number of women in menopause is increasing with increase in life expectancy and so is the increase in reported problems. Therefore the quality of life of this population becomes a major issue and understanding of menopause is very important issue for all the clinicians as most of the time it is a multidisciplinary approach. The major consequences 
of menopause are related primarily due to estrogen deficiency. Principal health concerns of menopausal woman include vasomotor symptoms, urogenital atrophy, osteoporosis, cardiovascular disease, cancer, cognitive decline and sexual problems.

Diseases of heart are the leading cause of death for women in most of the countries. Since 1984 the number of cardiovascular disease death for women has exceeded those of men. ${ }^{3}$ Major cardiovascular disease results from atherosclerosis in major vessels. The risk factors are the same for man and woman. They are family history of cardiovascular diseases, high blood pressure, smoking, diabetes mellitus, abnormal lipid profile and obesity. However, when controlling for these risk factors, men have a risk of developing coronary heart disease over 3.5 times that of women. With increasing age, this advantage is gradually lost and cardiovascular disease becomes the leading cause of death for both older women and older men. ${ }^{4}$ It is worth noting that there is a strong correlation between the magnitude of worsening in cardiovascular risk factors (lipid and lipoprotein changes, blood pressure, insulin levels) and the amount of weight gain during the menopausal transition. However weight gain at menopause is not an effect of hormonal changes, it reflects diet, exercise and ageing. ${ }^{5}$

As estrogen acts as an antioxidant due to its similarity of structure with vitamin $\mathrm{E}$, in a postmenopausal woman lack of estrogen and the simultaneous aging increases the oxidative stress. There is also decrease in antioxidant status in post menopausal women. ${ }^{6}$ This oxidative stress is due to generation of free radicals. These free radicals are capable of damaging virtually any bio molecules, including proteins, carbohydrate, lipids and nucleic acids. ${ }^{7}$ In the last few decades evidence has accumulated that a crucial and causative role in the pathogenesis of atherosclerosis is played by the free radical processes known as lipid peroxidation. It's believed that lipid peroxidation is involved in the oxidative modification of low density lipoprotein cholesterol (LDL-C) and ultimately results in the formation of atherosclerotic plaques. Much of the recent interest in oxidised LDL (oLDL) comes from the discovery that it exhibits properties in vitro that could the migration of monocyte macrophages into the intimal space and their conversion to foam cells. ${ }^{8}$

The thiobarbituric acid (TBA) assay is the most popular and easiest method used as an indicator of lipid peroxidation and free radical activity in biological samples. The assay is based upon the reaction of TBA with MDA, one of the aldehydes products of lipid peroxidation. ${ }^{9}$ Because some free radical production is inevitable in animal cells and because they can be very damaging, defenses against the deleterious actions of free radicals have evolved. These are known as antioxidant defenses. $\alpha$-Tocopherol is most widely distributed antioxidant in nature to scavenge free radicals by its ability to transfer phenolic hydrogen to a peroxyl free radical of preoxidized polyunsaturated fatty acid. Thus, acting as a first line of defence against peroxidation of polyunsaturated fatty acid contained in the cellular and subcellular membrane phospholipid. ${ }^{10}$

In contrast to $\alpha$-tocopherol ascorbic acid functions in an aqueous environment. As a free radical scavenge it directly accept single electron from superoxide, hydroxyl anion, as well as various lipid hydroperoxides. Thus due to its antioxidant action and its inhibiting action on glycosylation of protein ascorbic acid is very helpful in preventing diabetic complication. $\alpha$-tocopherol, selenium, glutathion peroxide and ascorbic acid interact with each other forming a stable antioxidant system. ${ }^{10}$

The present study is to evaluate the cardiovascular risk factors in postmenopausal women and their association with oxidative stress along with the cumulative effect of various risk factors.

\section{METHODS}

The study was conducted in the Department of Biochemistry, IMS and SUM Hospital, SOA University. Out of various cardiovascular risk factors four risk factors are chosen for the study. They were Fasting Blood sugar (FBS) $\geq 100 \mathrm{mg} / \mathrm{dl}$, Systolic Blood pressure (BP) $\geq 140$ and diastolic $\mathrm{BP} \geq 90 \mathrm{~mm}$ of $\mathrm{Hg}, \mathrm{BMI} \geq 25 \mathrm{~kg} / \mathrm{m}^{2}$, total cholesterol $\geq 200 \mathrm{mg} / \mathrm{dl}, \quad \mathrm{TG} \geq 150 \mathrm{mg} / \mathrm{dl}$ and HDL $\leq 40 \mathrm{mg} / \mathrm{dl}$. 50 postmenopausal women having any of the above risk factor were selected for the study from the Outpatient Department of Medicine and Gynecology. Another 50 post menopausal women were selected from the staff of the Hospital and some from the nearby localities without any known cardiovascular risk factors. All the 100 women selected for the study were in a narrow age range of 45 to 54 years to reduce the influence of age on the study. Any woman having one or more of the above selected risk factors were taken as a case. Women with any other risk factors like family history of cardiovascular diseases (CVD), previous CVD were excluded from the study. Again, women having history of smoking, alcohol intake, major illness in recent pass, major surgery in recent past and taking antioxidant medication were excluded from the study. All study subjects were informed about the study and their consent was taken before the general and biochemical examination. The above study was cleared from the ethical committee of the institution.

All subjects of the study were undergone through general examination and $10 \mathrm{ml}$ of blood was taken from each individual through antecubital venipuncture. Care was taken to do all biochemical test on the same day of collection. FBS, Serum total cholesterol, TG, HDL was measured by COBAS INTEGRA 400 Autoanalyzer by enzymatic colorimeter methods. ${ }^{11}$ Blood pressure was measured by standard sphygmomanometer with left arm supine position 3 time half hour interval and mean BP was calculated. BMI was calculated by dividing the body 
weight in kilogram by the square of height in meter. Serum MDA was measured by KEI Satoh et al method. ${ }^{12}$ Vitamin C was measured by converting it first into dehydro-ascorbic acid and then was coupled with 2,4dinitrophenyl hydrazine in presence of thiourea as mild reducing agent to produce 2,4- dinitrophenyl hydrazone which is later converted to a red-coloured compound by sulphuric acid and measured colorimetrically. ${ }^{13}$ For measurement of vitamin $\mathrm{E}$ it was first extracted into xylene and then converting it to a red coloured compound with $\alpha, \alpha$-dipyridil. A correction for the carotene is made after adding ferric chloride and reading was taken at $520 \mathrm{~nm}$ in a colorimeter. ${ }^{14}$

\section{RESULTS}

Results were analysed by Microsoft excel and SPSS 20.0.

In the study both cases and controls were divided into three categories of 40-44 year, 45-49 year and 50-54 year. More number of cases were found in the higher age group where as more number of controls were found in the lower age group. The mean age of cases was $48.52 \pm 3.38$ year and that of controls are $44.58 \pm 3.05$ year (Table 1). Cases had a higher mean age in comparison to controls.

Table 1: Age distribution of cases and controls.

\begin{tabular}{|lll|}
\hline Age in yr & Control (50) & Cases (50) \\
\hline $40-44$ & 25 & 6 \\
\hline $45-49$ & 20 & 23 \\
\hline $50-54$ & 5 & 21 \\
\hline Mean & $44.58 \pm 3.05$ & $48.52 \pm 3.38$ \\
\hline Mean age of menopause & $42.22 \pm 2.8$ & $45.04 \pm 2.61$ \\
\hline
\end{tabular}

According to a study in Chinese women there was a progressive increase with age in the prevalence of glucose intolerance, hypertension, dyslipidaemia and obesity. These findings suggest that age had an important and independent effect on cardiovascular risk in Chinese women and that, as in Caucasians, the onset of menopause might further increase this risk. ${ }^{15}$ These finding suggest that age has an important and independent effect on cardiovascular risk in women.

In our study both cases and controls were taken in a narrow range of 40 to 55 year to minimize the influence of age on oxidative stress. The mean age of menopause of cases is 45.04 \pm 2.61 years and controls are 42.22 \pm 2.8 years where as the average age of all the women included in the study were $43.42 \pm 3.15$ years. [Table-1] Study by Bharadwaj JK and Vaidya PR shows the mean age of menopause of Indian women is 45.03 years and a study conducted by Institute for Social and Economic change Bangalore shows the mean age of menopause in Indian women is 44.3 years. ${ }^{16,17}$ According to F. Fickinson, T. Castillo, L. Vales and L. Uc, living in the best socioeconomic conditions, have the oldest mean age of menopause. ${ }^{18}$ Again study by Hidayat NM et al., it revealed that the semi urban women reached menopause significantly earlier than urban ones. ${ }^{19}$ Somehow lower mean of menopause in our study may be due to low socioeconomic status of the area. Some genetic and environmental factors may also play role in early menopause of Indian women.

Higher fasting plasma glucose level, hypertension, high BMI and hyperlipidemia was observed in $28 \%, 32 \%$, $22 \%$, and $46 \%$ of cases included in the study respectively. 37 cases $(74 \%)$ had only one of the risk factors taken in the study and rest $26 \%$ (13 cases) carry more than one risk factors (Table 2). No definite opinion on risk prevalence can be derived as the study carried out in a small group of women compared to population and for a short period of time.

Table 2: Prevalence of risk factors in cases studied.

\begin{tabular}{|llll|}
\hline $\begin{array}{l}\text { Risk } \\
\text { factors }\end{array}$ & Total cases & $\begin{array}{l}\text { With single } \\
\text { factor }\end{array}$ & $\begin{array}{l}\text { With multiple } \\
\text { risk factors }\end{array}$ \\
\hline FBS & 14 & 8 & 6 \\
\hline BP & 16 & 8 & 8 \\
\hline BMI & 11 & 6 & 5 \\
\hline LIPID & 23 & 17 & 6 \\
\hline
\end{tabular}

\section{DISCUSSION}

Reactive oxygen species are increased by hyperglycemia. Hyperglycemia, which occurs during diabetes (both type 1 and type 2) and, to a lesser extent, during insulin resistance, causes oxidative stress. Free fatty acids, which may be elevated during inadequate glycemic control, may also be contributory. ${ }^{20}$ Freilas JP found significant increase in lipid peroxidation product in diabetes mellitus patients as compared to normal individual. ${ }^{21}$ Increasing evidence exists, suggesting an important role for oxidative stress in the pathogenesis and progression of hypertension in women via a decrease of NO production after menopause. ${ }^{22}$

It was also found that obesity is associated with glucose intolerance, hypertension and hypertriglyceridaemia. All are known cardiovascular risk factors. Studies by Francesco Perticone et al. shows that there is increased oxidative stress in obese persons and vitamin $\mathrm{C}$ has beneficial role in obese to reduce its complications. ${ }^{23}$ Alteration of plasma lipids and lipoprotein level are common risk factors for CHD and increase cardiovascular mortality. Decrease HDL cholesterol appears to be the major lipid risk factor in women, with increased HDL being negatively associated with subsequent coronary disease. The incidence of hyperlipidemia increases after menopause. TG also appears to be an independent risk factor in women. An extensive review of various studies shows that postmenopausal women tend to have more atherogenic lipoprotein profile showing higher level of total cholesterol, TG, LDL and VLDL. ${ }^{24}$ 
Vitamin E is a fat-soluble antioxidant that stops the production of ROS formed when fat undergoes oxidation. Study by Nagyova A et al, shows decrease in cardiovascular disease risk in post-menopausal women taking long term vitamin E supplementation. ${ }^{25}$ Decrease in serum vitamin $\mathrm{E}$ in postmenopausal women and in cardiovascular disease is also observed in other studies. ${ }^{26}$ As a water-soluble antioxidant, vitamin $\mathrm{C}$ is in a unique position to "scavenge" aqueous peroxyl radicals before these destructive substances have a chance to damage the lipids. It works along with vitamin E, a fat-soluble antioxidant, and the enzyme glutathione peroxidase to stop free radical chain reactions. Vitamin $C$ supports the cardiovascular system by facilitating fat metabolism and protecting tissues from free radical damage, and it assists the nervous system by converting certain amino acids into neurotransmitters. ${ }^{27}$ As an antioxidant and a constituent of collagen, vitamin $\mathrm{C}$ may play a number of roles in maintaining cardiovascular fitness. The fatty plaques that form in blood vessels, called atherosclerosis, are a major contributor to heart disease; Vitamin $\mathrm{C}$ may prevent this plaque formation by inhibiting the oxidative modification of low density lipoproteins (LDLs). Beyond that, vitamin $\mathrm{C}$ may play a mitigating role in another aspect of atherosclerosis - the buildup and adhesion of platelets on vessel walls.

Cases with single risk factor was measured separately and was evaluated applying ANOVA to them and it was found that the effect of risk factors (FBS, BP, BMI, Hyperlipidemia) on MDA, vitamin $\mathrm{E}$ and vitamin $\mathrm{C}$ were comparable but none has significant influence on the oxidative markers in comparison to others (Table 3).

Table 3: Biochemical parameters with individual risk factor in cases.

\begin{tabular}{|llll|}
\hline $\begin{array}{l}\text { Risk } \\
\text { factors }\end{array}$ & $\begin{array}{l}\text { MDA } \\
(\mu \mathrm{mol} / \mathrm{L})\end{array}$ & $\begin{array}{l}\mathrm{E} \\
(\mu \mathrm{mol} / \mathrm{L})\end{array}$ & $\mathrm{C}(\mu \mathrm{mol} / \mathrm{L})$ \\
\hline FBS $(8)$ & $2.71 \pm 0.5$ & $20.72 \pm 2.15$ & $27.14 \pm 2.95$ \\
\hline BP $(8)$ & $3.04 \pm 0.55$ & $19.56 \pm 0.65$ & $27.23 \pm 3.36$ \\
\hline BMI (6) & $2.75 \pm 0.59$ & $20.38 \pm 1.63$ & $28.45 \pm 1.88$ \\
\hline $\begin{array}{l}\text { Lipid } \\
\text { profile (17) }\end{array}$ & $2.75 \pm 0.66$ & $20.77 \pm 1.63$ & $26.61 \pm 2.03$ \\
\hline F value & 0.37 & 0.88 & 0.62 \\
\hline
\end{tabular}

Study by Rumley AG et al, shows that among the risk factors TG has highest impact on lipid peroxidation and subsequent oxidative stress and Blood Pressure has no impact on oxidative stress. ${ }^{28}$ But our study did not find significant impact of any particular risk factor in comparison to other risk factors on lipid peroxidation.

However MDA value found in cases with multiple risk factors $(3.53 \pm 0.79)$ when compared with that of cases with single risk factor $(2.84 \pm 0.57)$ was found to be statistically significant $(\mathrm{P}<0.001)$. Similarly, the decrease in vitamin $\mathrm{E}$ in cases with multiple risk factors $(19.93 \pm 0.78)$ when compared with single risk factor cases
(20.45 \pm 1.62$)$ was found to be significant $(\mathrm{P}<0.01)$. It was also found that vitamin $\mathrm{C}$ in women with multiple risk factors was decreased in comparison to women with a single risk factor $(25.19 \pm 4.21$ vs $27.13 \pm 2.5)$ and was significant $(\mathrm{P}<0.001)$ (Table 4$)$. So oxidative stress increases significantly when multiple risk factors are present in our study. Study by Berenson GS, et al. found that as the number of cardiovascular risk factors increases, so does the severity of asymptomatic coronary and aortic atherosclerosis in young people. ${ }^{29}$

Table 4: Comparison between cases with single risk factor and cases with multiple risk factors.

\begin{tabular}{|lllll|}
\hline $\begin{array}{l}\text { Parameters } \\
(\mu \mathrm{mol} / \mathrm{L})\end{array}$ & $\begin{array}{l}\text { Single risk } \\
\text { factor }\end{array}$ & $\begin{array}{l}\text { Multiple } \\
\text { risk } \\
\text { factors }\end{array}$ & $\mathbf{z}$ & $\mathbf{p}$ \\
\hline MDA & $2.84 \pm 0.57$ & $3.53 \pm 0.79$ & 8.56 & $<0.001$ \\
\hline $\mathrm{E}$ & $20.45 \pm 1.62$ & $19.93 \pm 0.87$ & 2.26 & $<0.05$ \\
\hline $\mathrm{C}$ & $27.13 \pm 2.5$ & $25.19 \pm 4.21$ & 5.54 & $<0.01$ \\
\hline
\end{tabular}

\section{CONCLUSION}

Basically, the study intended to find the age of menopause in the local community along with the association of various cardiovascular risk factors. It was noted that the mean age of menopause of the locality is lower than the national mean. Again, it was noted that not a single risk factor is more prone to increase the oxidative stress in comparison to other though each risk factor has contribution role in increase oxidative stress. So, it may be concluded that all the risk factors are equally important for the morbidity and mortality in CVD. Again, presence of multiple risk factors increases the oxidative stress more than a single one which imply that presence of multiple risk factors increases the morbidity and mortality. Extensive study is needed on wider population group to further justify the findings and also role of antioxidant medication to decreases the morbidity and mortality.

\section{Funding: No funding sources \\ Conflict of interest: None declared \\ Ethical approval: Not required}

\section{REFERENCES}

1. Kumar P, Malhotra N, Menopause, Jeffcoates principle of Gynaecology, $7^{\text {th }}$ Ed. 2008;862-883.

2. Morse CA, Smith A, Dennerstein L, Green A, Hopper J, Burger H. The treatment-seeking woman at menopause. Maturitas. 1994 Mar 1;18(3):161-73.

3. The American heart association, Cardiovascular disease statistics. Available at: http://www.americanheart.org.2003.

4. Fritz MA, Speroff L. Menopause and perimenopausal transition. In Clinical Gynecologic Endocrinology and Infertility, $8^{\text {th }}$ Ed., 2011:673-748.

5. Wing RR, Matthews KA, Kuller LH, Meilahn EN, Plantinga PL. Weight gain at the time of menopause: 
Arch. Intern. Med. 1991 151/1 (97-102). Maturitas. 1991 Oct 1;13(4):339-40.

6. Guetta V, Cannon RO. Cardiovascular effects of estrogen and lipid-lowering therapies in postmenopausal women. Circulation. 1996 May 15;93(10):1928-37.

7. Leibovitz BE, Siegel BV. Aspects of free radical reactions in biological systems: aging. $\mathrm{J}$ of Gero. 1980 Jan 1;35(1):45-56.

8. Quinn MT, Parthasarathy S, Fong LG, Steinberg D. oxidatively modified low density lipoproteins: A potential role in recruitment and retention of monocyte/macrophages during athrerogenesis. Proc Natl Acad sci USA. 1987;84:2995-8.

9. Esterbauer $\mathrm{H}$, Cheeseman $\mathrm{K}$. Determination of aldehydic lipid peroxidation products: Malondialdehyde and 4-hydroxynonenal. Methods Enzymol. 1990;186:407-21.

10. Peter A, Mayes. Structure and function of lipid soluble vitamins. Harper Biochemistry; 25 $5^{\text {th }}$ Edi. 2009:642-652.

11. Roche Cobas Integra 400 Method Manual, $8^{\text {th }}$ Edition; 2013:01.

12. Satoh K. Serum lipid peroxide in cerebrovascular disorders determined by new colorimetric method. Clin. Chim. Acta. 1978;90:37-43.

13. Roe. Plasma Vitamin C by 2-4 dinitrophenyl hydrazone method, Harold Varley; Practical Clinical Biuochemistry. $4^{\text {th }} \mathrm{Ed} ; 1$ 1961:635.

14. Baker and Frank. Varleys Practical Clinical Biochemistry, $6^{\text {th }} \mathrm{Ed} ; 1968: 902$.

15. Ko GT, Chan JC, Woo J, Lau EM, Yeung VT, Chow $\mathrm{CC}$, et al. The effect of age on cardiovascular risk factors in Chinese women. Int J of Car. 1997 Oct 10;61(3):221-7.

16. Bharadwaj JA, Kendurkar SM, Vaidya PR. Age and symptomatology of menopause in Indian women. $\mathbf{J}$ Postgrad Med. 1983;29:218.

17. India-based Institute for Social and Economic Change, London's Times reports, 28. January 2007; 14:08.

18. Fickinson F, Castillo T, Vales, Uc L. International J of Antropology, 1995;10(1):21-8.

19. Hidayet NM, Sharaf SA, Aref SR, Tawfik TA, Moubarak II. Correlates of age at natural menopause: a community-based study in Alexandria. 1999;5(2):307-19.
20. George L. King and Mary R. Loeken. J of Histochemistry and Cell Biology, Oct, 2004;122(4):333-8.

21. Freitas JP, Filipe PM, Rodrigo FG. Lipid peroxidation in type 2 normolipidemic diabetic patients; Diabetes Res Cli Pract. 1997 May;36(2):715.

22. Pialoux V, Brown AD, Leigh R, Friedenreich CM, Poulin MJ. Effect of cardiorespiratory fitness on vascular regulation and oxidative stress in postmenopausal women. Hypertension. 2009 Nov $1 ; 54(5): 1014-20$.

23. Perticone F, Ceravolo R, Candigliota M, Ventura G, Iacopino S, Sinopoli F, et al. Obesity and body fat distribution induce endothelial dysfunction by oxidative stress: protective effect of vitamin C. Diabetes. 2001;50:159-65.

24. Matthews KA, Meilahn E, Kuller LH, Kelsey SF, Caggiula AW, Wing RR. Menopause and risk factors for coronary heart disease. New England J of Med. 1989 Sep 7;321(10):641-6.

25. Nagyova A, Mongiellova V, Krivosikova Z, Blazicek P, Spustova V, Gajdos M, et al. Physiological Research J. 2002;51(5):457-64.

26. Torun M, Avci N, Yardim S. Serum levels of vitamin $\mathrm{E}$ in relation to cardiovascular diseases. J Clin Pharm Ther. 1995;20:335-40.

27. Frei B, England L, Ames BN. Ascorbate is an outstanding antioxidant in human blood plasma. Proc Natl Acad Sci USA. 1989;86:6377-81.

28. Rumley AG, Woodward M, Rumley A, Rumley J, Lowe GDO. Plasma lipid peroxides: relationships to cardiovascular risk factors and prevalent cardiovascular disease, QJM. 2004;97(12):809-16.

29. NHLBI Obesity Education Initiative Expert Panel. Clinical Guidelines on Identification, Evaluation, and Treatment of Overweight and Obesity in Adults: The Evidence Report. Bethesda, Md: National Institutes of Health, National Heart, Lung, and Blood Institute; 1998.

Cite this article as: Tripathy SK, Mishra PK. Effect of various cardiovascular risk factors on oxidative stress markers in post menopausal women. Int $\mathbf{J}$ Basic Clin Pharmacol 2017;6:1768-72. 